\title{
Humor e Significação: Revisitando Bases Teóricas ${ }^{1}$
}

\author{
Sayonara Abrantes de Oliveira Uchoa ${ }^{1}$; Symara Abrantes Albuquerque de Oliveira ${ }^{2}$;
} Henrique Miguel de Lima Silva ${ }^{3}$; Gislene Farias de Oliveira ${ }^{4}$

\begin{abstract}
Resumo: Objetiva, apresentar reflexões realizadas no que tange à relação produtiva entre fenômenos de construção do humor e a significação, sobretudo sob um olhar do ensino de leitura e nas relações inferenciais. Fruto de uma pesquisa maior, será apresentado neste artigo apenas a fase bibliográfica do estudo, momento em que foram revisitados teóricos a exemplo de Raskin (1985), Veatch (1998), Possenti (2010, 1998), Ilari (2012, 2011, 2000), Marcuschi $(2011,2008$, 2007) e Koch (2012), entre outros, estabelecendo um caráter exploratório. Contribui, pois, para o despertar de reflexões sobre os entrecruzamentos teóricos entre as contribuições inerentes ao humor, aos processos de leitura e de ensino.
\end{abstract}

Palavras-chave: Humor. Significação. Ensino.

\section{Humor and Meaning: Revisiting Theoretical Bases}

\begin{abstract}
It aims to present reflections regarding the productive relationship between humor-building phenomena and meaning, especially under a reading teaching and relations inferential As a result of a larger research, only the bibliographical phase of the study will be presented in this article, when theorists were revisited, such as Raskin (1985), Veatch (1998), Possenti (2010, 1998), Ilari (2012, 2011, 2000 ), Marcuschi $(2011,2008,2007)$ and Koch (2012), among others, establishing an exploratory character. It contributes to the awakening of reflections on the theoretical intersections between the contributions inherent to humor, to the processes of reading and teaching.
\end{abstract}

Keywords: Humor. Meaning. Teaching.

\footnotetext{
${ }^{1}$ Doutoranda e Mestre em Linguística pela UFPB\PROLING, pesquisadora nas áreas de Semântica e Linguística Aplicada. Possui graduação em LICENCIATURA PLENA EM LETRAS pela Universidade Federal de Campina Grande (2003). Atualmente é professora efetiva do Instituto Federal de Educação, Ciência e Tecnologia da Paraíba- Campus Cajazeiras - PB. Contato: sayonarauchoa@ifpb.edu.br;

${ }^{2}$ Graduação em Enfermagem pela Universidade Federal de Campina Grande (2011). Especializações em: Saúde da Família, Obstetrícia, Gestão e Metodologias ativas. Mestrado multiprofissional em Sistemas Agroindustriais com ênfase na saúde. Cursando Doutorado em Ciências da Saúde pela Santa Casa da Misericórdia de São Paulo. Instituto Federal da Paraíba - IFPB. Contato: Instituto Federal da Paraíba - IFPB. Contato: symaraabrantes_@hotmail.com/symara_abrantes@hotmail.com;

${ }^{3}$ Graduação em Letras, Português, Inglês e suas Literaturas pela Universidade de Pernambuco UPE. Especialista em Linguística Aplicada ao Ensino de Língua Portuguesa pela Fundação de Ensino Superior de Olinda FUNESO. Especialista em Psicopedagogia Institucional pelo Centro Integrado de Pesquisa e Tecnologia CINTEP. Mestre e Doutorando em Linguística pelo Programa de Pós-Graduação em Linguística da Universidade Federal da Paraíba PROLING/UFPB. Contato: Henrique.miguel.93@hotmail.com;

${ }^{4}$ Psicóloga. Doutorado em Psicologia social pela UFPB. Professora da Universidade Federal do Cariri. Faculdade de Medicina. Contato: gislenfarias@gmail.com.
}

\footnotetext{
${ }^{1}$ Este trabalho constitui-se de um recorte da pesquisa de mestrado de Sayonara Abrantes de Oliveira Uchoa, defendida em 2013, pela UFPB.
}

22 Id on Line Rev. Mult. Psic. V.12, N. 42, p. 22-37, 2018 - ISSN 1981-1179
Edição eletrônica em http://idonline.emnuvens.com.br/id 


\section{Introdução}

Dedicamo-nos à discussão acerca das bases teóricas relacionadas ao humor, enquanto objeto de estudo, como também dos fenômenos constitutivos da significação nas tirinhas humorísticas, sob o pressuposto de que através da compreensão desses elementos o leitor tem à disposição condições para o desenvolvimento da compreensão leitora.

Ressaltamos que o foco deste trabalho, inserido na Linguística Aplicada, situa-se na contribuição dos gêneros de humor para o desenvolvimento da leitura. Reiteramos, ainda, que a discussão aqui delineada não se propõe à produção de textos humorísticos na escola, mas ao reconhecimento da riqueza de fenômenos mobilizados em sua construção e, por tal, disponíveis enquanto recursos significativos a serem inferidos por leitores proficientes.

Nestes termos, discutir humor e significação é fundamental, visto que a compreensão dos fenômenos constitutivos do humor é condição para analisar a relevância destes, no ensino de leitura, pressuposto norteador deste estudo.

Convictos da importância da inserção do humor no ensino, não para estimular a formação de humoristas, mas a de leitores, buscamos bases teóricas para caracterizá-lo e, em seguida, reconhecer nas tirinhas humorísticas, gênero textual delimitado para o estudo, os processos de construção da significação amparados na Linguística textual, na Semântica e na Pragmática.

\section{Percursos da Construção do Humor}

O estudo do humor não é recente, remonta à Antiguidade e à tradição filosófica em Platão, Aristóteles, Cícero e Quintiliano (ALBERTI, 1999). No entanto, ressaltamos que sua dimensão estende-se aos campos da Psicologia, da Psicanálise, da Linguística, da Antropologia, caracterizando-se como temática de abrangência multidisciplinar (DIAS, 2011, p. 207).

Fundamentando-se nos postulados da Psicologia, Freud (1959) contemplou o humor e sua importância na vida psíquica dos indivíduos e, a partir dessa visão, buscou analisar os traços constitutivos do humor chegando, segundo Rosas (2003, p. 140), à seguinte proposição: 
(...) na construção do chiste, os processos são basicamente análogos aos que se verificam na elaboração onírica: em ambos os casos, encontram-se condensações, deslocamentos, unificações, representações e omissões, e que, além disso, todos esses processos são caracterizados por uma forte tendência à economia. Quanto à função, Freud conclui que, da mesma forma que o sonho, o chiste se destina à satisfação de um desejo ou, em última instância, à produção de prazer. Além disso, constitui um processo de defesa que, ao contrário do recalque, é saudável porque permite o acesso ao consciente dos conteúdos associados ao sentimento penoso que lhe dá ensejo, encontrando uma forma de converter em prazer a energia psíquica preparada para investimento no desprazer.

Neste sentido, segundo Freud, é através do humor e do riso que se estabelece o alívio, constituindo-se em uma defesa contra o desprazer, numa abordagem psicanalítica. Em sua teoria, deixa claro, ainda, que “(...) o chiste reside realmente na expressão verbal” (1959, p. 46) e que "(...) o caráter do chiste depende da forma expressiva" (1959, p. 88). Diante do exposto, Rosas (2003, p. 140) ressalta que, embora Freud tenha manifestado a percepção no humor verbal, não se deteve neste propósito por ter discorrido, com maior interesse, sobre a intervenção do humor no inconsciente humano, como também, por admitir que o humor consiste em um fenômeno de base cultural e histórica.

Rosas (2003, p. 135) discute que os primeiros registros conceituais acerca do humor, no sentido hoje analisado, remontam à virada do século XX, com Bergson (1983), no ensaio sobre Significação e Comicidade. Para esse filósofo, "não há comicidade fora daquilo que é propriamente humano. Uma paisagem pode ser bela, graciosa, sublime, insignificante ou feia; nunca será risível. Rimos de um animal, mas por termos surpreendido nele uma atividade humana ou uma expressão humana" (BERGSON, 2001, p. 02).

O que nos chama a atenção, na visão de Bergson (1983), é a percepção da emoção como um verdadeiro antídoto para o riso, estabelecendo que a compreensão do humor dá-se pela inteligência pura, pela vertente racional, situação por ele exemplificada:

\footnotetext{
Numa sociedade de puras inteligências provavelmente não mais se choraria, mas talvez ainda se risse; ao passo que almas invariavelmente sensíveis, harmonizadas em uníssono com a vida, nas quais qualquer acontecimento se prolongasse em ressonância sentimental, não conheceriam nem compreenderiam o riso. (BERGSON, 2001, p. 03)
}

Apoiamo-nos na visão apresentada para reafirmarmos que os textos de humor requerem do leitor a mobilização de um maior contingente de habilidades de leitura, tendo em vista a prevalência dos implícitos e a complexidade de fenômenos envolvidos em sua construção. 
A esse respeito, destacamos que muitos são os estudos que enfatizam a importância do humor e sua função por considerar, segundo Travaglia (1989, p. 670), que "O humor tem sido visto como uma atividade ou faculdade humana universal, cuja função vai muito além do simples fazer rir" e, por tal, um campo de estudo transdisciplinar. Nessa visão, o humor constitui-se um instrumento de denúncia e desmistificação social criado pelo homem e cujos instrumentos constitutivos são de grande riqueza para os estudos linguísticos.

Ancorados no valor expresso por Travaglia (1989), destacamos não ser nosso propósito fazer comparações entre gêneros ou avaliá-los, mas de reconhecer que muitos deles têm seus aspectos da significação desenvolvidos de forma mais direta e linear, favorecendo uma leitura fluida e clara.

Já nas tirinhas, a compreensão do humor ocorre pela capacidade do leitor em estabelecer as relações necessárias entre os constituintes textuais e discursivos mobilizados, valendo-se de suas habilidades cognitivas e de atitudes inferenciais.

Em sua obra datada de 1983, Bergson visualiza o humor por uma vertente mais filosófica e racional, pautando-se no aspecto central da sua discussão, cuja arte de fazer rir está relacionada à mecanicidade e rigidez do corpo (humano) em oposição à flexibilidade dos movimentos. (SILVA, 2006, p. 24)

Ressalte-se que a teoria desenvolvida por Bergson não atribui à linguagem a construção da comicidade, dando-lhe papel secundário ao afirmar que "...a comicidade da linguagem deve corresponder, ponto por ponto, à comicidade das ações e das situações e (...) ela não passa da projeção delas no plano das palavras" (BERGSON, 2001, p. 61).

Embora não tenha atribuído ao campo das palavras o espaço à construção do humor, sua teoria contribuiu para a Semântica do Humor, segundo afirma Magalhães (2010) que, retoma as reflexões de Raskin (1985) que estabelece a distinção entre o humor expresso e o humor criado. Em sua obra, "Raskin acredita que ambas as formas, natural e espontânea, correspondem ao humor espontâneo, portanto não-intencional, enquanto o humor criado admite determinadas intenções e situações que direcionam a construção do humor" (MAGALHÃES, 2010, p. 26).

Ferraz (2012, p. 98-99) explica, ancorando-se em Raskin (1985), que os fatores que contribuem para um ato de humor são:

(...) a participação dos seres humanos no ato (locutor/interlocutor); o estímulo que deve ser apresentado e correspondido como condição necessária e suficiente para o humor; a experiência de vida das pessoas, que é importante fator para o riso; o fator psicológico, ou seja, o grau de predisposição individual do humor; o contexto 
situacional, que determina a significação semântica da piada verbal e o papel da sociedade, pois o humor é compartilhado por membros de um determinado grupo social, dentro de uma certa cultura, com seus valores, crenças e normas. ${ }^{2}$

Através da visão apresentada acerca dos fatores que contribuem para o humor, verificamos que esse contempla aspectos das áreas do conhecimento da Psicologia, da Sociologia e da Filosofia, aspecto esse percebido por Veatch (1998, p. 162), ao expor que "Theories of humor do not tend to respect disciplinary boundaries, though writers often address themselves to the concerns of disciplinarily-restricted audiences"3.

Percebemos, nesse ensejo, que o estudo acerca da percepção do humor não estabelece limites para as áreas do conhecimento, havendo apenas focos diferenciados, olhares sobre o humor por diferentes perspectivas. Neste estudo, abordaremos os textos de humor pelo olhar da Linguística Aplicada ao ensino da língua.

Considerando que os gêneros de humor carregam em sua construção tamanha riqueza de fenômenos textuais e discursivos na construção da significação, concordamos que correspondem a verdadeiros desafios aos leitores. Em Ferraz (2012, p. 99), é enfatizada a importância dos estudos linguísticos do humor, sobretudo nas áreas da Semântica e da Pragmática, conforme expresso por Raskin (1985), pelo fato de tais áreas tratarem de aspectos conceituais como pressuposição, implicações, implicaturas, atos de fala, inferências, estratégias conversacionais e mundos possíveis; temáticas fundamentais à compreensão dos mecanismos do humor e da competência ${ }^{4}$ leitora desses gêneros textuais.

Ressaltamos, pois, duas teorias fundamentais visto que estabelecem o suporte teórico para a compreensão do humor na atualidade, haja vista que, segundo Magalhães (2010), complementam-se quando a segunda acrescenta à primeira a possibilidade de compreender o humor para além do verbal. Trata-se da Semantic Script Theory of Verbal Humor", Teoria Semântica dos Scripts do Humor Verbal ${ }^{5}$, de Victor Raskin (1985), e a Theory of Humor, Teoria do Humor, de Thomas Veacht (1998).

\footnotetext{
${ }^{2}$ Grifos do autor.

3 "Teorias do humor não tendem a respeitar as fronteiras disciplinares, embora alguns pesquisadores dirijam suas preocupações a um público disciplinar restrito.” (VEATCH, 1998, p. 162) (Tradução nossa)

${ }^{4}$ Para Rojo (2009), a menção aos termos capacidades / competências / habilidades é intercambiável. Retomando Koch (2012), adotamos a percepção de que a competência está relacionada com o "saber fazer" ao passo que as habilidades com o "como fazer", isto é, como o indivíduo mobiliza recursos, toma decisões, adota estratégias ou procedimentos e realiza ações concretas para resolver os problemas. Portanto, competência e habilidades são duas dimensões interdependentes do "saber", que se completam mutuamente. No âmbito da leitura e da interpretação de textos, a competência leitora se expressa por meio de habilidades de leitura, que, por sua vez, se concretizam por meio de operações ou esquemas de ação, ou seja, a capacidade leitora demonstra-se na compreensão.

5 Também conhecida como Teoria dos Scripts ou teoria dos Esquemas Incompatíveis.
} 
Acreditamos que a associação das teorias citadas vem contemplar aspectos teóricos necessários ao presente estudo, uma vez que o gênero tirinha constitui-se de aspectos linguísticos verbais, contemplados em Raskin (1985), como também dos não verbais, acrescidos à teoria dos scripts, por Veacht (1998). Também contribuirão as reflexões de Possenti (1998), Rosas (2003) e Travaglia (1989), cujos estudos encontram-se ancorados em seus predecessores ${ }^{6}$.

Na Semantic Script Theory of Verbal Humor, ou seja, "Teoria dos dois Scripts", Victor Raskin (1985) constitui uma teoria de base semântica na qual o texto humorístico é construído a partir da existência de dois scripts que, embora distintos, tornam-se compatíveis. Para a compreensão da teoria, faz-se necessário entender que um script condiz a:

\begin{abstract}
...feixe de informações sobre um determinado assunto ou situação, como rotinas consagradas e modos difundidos de realizar atividades, consistindo numa estrutura cognitiva internalizada pelo falante que lhe permite saber como o mundo se organiza e funciona. Tais informações apresentam-se em sequências tipicamente estereotipadas, predeterminadas, e, como tais, além de serem objetos cognitivos, os scripts estão intimamente relacionados a itens lexicais e podem ser por eles evocados. (ROSAS, 2003, p. 140)
\end{abstract}

Pelo exposto, compreende-se que o humor é construído pela oposição de scripts que, por sua vez, são roteiros cuja sobreposição gera certa incongruência ou oposição. Raskin (1985) defende, ainda, a existência de scripts que dependem, fundamentalmente, dos aspectos linguísticos ativados através do conhecimento lexical e, como também daqueles que dependem do conhecimento de mundo, ou seja, das informações enciclopédicas partilhadas entre os falantes. A leitura proporcionada por eles gera uma série de interpretações possíveis, cuja percepção daquela pretendida pelo texto consiste na identificação do gatilho semântico.

Para Raskin (1987, p. 17), existem ingredientes semânticos fundamentais para a caracterização de um chiste:

a) Uma mudança do modo de comunicação bona-fide para o modo não bona-fide de contar piadas; b) o texto considerado chistoso; c) dois scripts (parcialmente) superpostos compatíveis com o texto; d) uma relação de oposição entre os dois scripts; e) um gatilho, óbvio ou implícito, que permite passar de um script para outro.

É notório que, além da percepção das relações opositivas e dos propósitos comunicacionais, da intenção, Raskin (1987) agrega a essa visão a presença de um "gatilho",

\footnotetext{
${ }^{6}$ As contribuições destes e de outros estudiosos brasileiros, aqui mencionados, encontram base teórica nas teorias de Bergson (1983), Freud (1959) e Raskin (1985, 1987).
} 
“...elemento integrante de qualquer piada que apresente dois aspectos semânticos distintos: ambiguidade e contradição e podendo ser entendido como o elemento capaz de introduzir o segundo discurso à sombra do primeiro" (MAGALHÃES, 2010, p. 29).

Além dos aspectos semânticos, Travaglia (1990, p. 24) aponta como mecanismos pragmáticos do humor "a suspensão do senso comum e o fato do humor ser comunicação nãoconfiável (não bona-fide) ’. Por essa visão, a construção do humor ocorre através da interação entre leitor e autor através do texto, ou seja, através da percepção dos implícitos, dos atos de fala inacabados e da capacidade do leitor perceber os sentidos pretendidos pelo autor dentre os possíveis de serem construídos inferencialmente, no texto.

A esse respeito, Possenti (2010, p. 61) explica que as técnicas humorísticas fundamentais promovem a permissão da descoberta de outro sentido, de preferência inesperado, frequentemente distante daquele que é expresso em primeiro plano e que, até o desfecho da piada, parece ser o único possível.

Possenti (1998, p. 91) explicita que “...o humor deriva de frames incompatíveis, embora não claramente expressos por personagens presentes na piada, mas que os leitores de alguma forma (re)conhecem. A esse propósito, Magalhães (2010, p. 29) reitera que “...o desafio do humor é construir um texto evocando outro, texto que apresentará uma oposição em suas proposições, deflagradas pelo jogo de significados por via de elementos semânticos”.

Por esse limiar, Possenti (1998) estabelece o que chama de "esboço de mecanismos envolvidos na piada", classificando-os por níveis fonológicos, morfológicos, sintáticos, lexicais, semânticos, pragmáticos, enfim, estabelecendo uma base linguística para a compreensão do humor verbal.

Segundo Attardo (1994, p. 222 apud Rosas, 1993, p. 143), em 1991, Raskin revisou a teoria inicialmente proposta, juntamente com Attardo, momento no qual sua teoria semântica de scripts no humor passou a chamar-se General Theory of Verbal Humor, Teoria Geral do Humor Verbal, para destacar que, além da semântica, a nova teoria considera "outras áreas da linguística, inclusive e principalmente a linguística textual, a teoria da narratividade e a pragmática".

No entanto, fica claro que as teorias discutidas em Raskin, Possenti e Travaglia detêmse nos aspectos linguísticos do texto verbal, fato que nos leva a buscar para além delas, visto que o gênero tirinha agrega aspectos não verbais, contemplados por Veatch (1998), em A theory of Humor, Uma teoria do Humor. 
Segundo Magalhães (2010), a teoria de Veatch (1998) contribui para o estudo do humor ao agregar uma visão acerca do texto não verbal, aspecto não discutido em Raskin e Attado (1991).

Para Veatch (1998, p.162), o humor consiste em certo estado psicológico tendecioso à produção do riso. No entanto, a produção do riso, através do texto, é intencional e construída pela sobreposição de scripts, sejam esses no plano linguístico verbal ou não verbal. Assim, esses dois campos interagem na construção da significação em gêneros que os contemplam. Acerca da teoria supracitada, Magalhães (2010, p. 33) explicita em relação a Veatch (1998):

\begin{abstract}
O linguísta organiza e nomeia os scripts de Raskin, os quais considera condições de produção, avançando assim a teoria raskiniana. Essas condições são: (a) Normalidade (N) - script um da teoria de Raskin - , (b) Violação (V) - segundo script da teoria de Raskin - e (c) Simultaneidade (S) - sobreposição simultânea dos scripts. Essas condições, segundo Veatch, individualmente necessárias e conjuntamente suficientes descrevem um estado subjetivo de absurdidade emocional, porque uma situação é percebida como normal, mas simultaneamente alguma crença ou algum princípio moral subjetivo, que deve ser respeitado como ele espera é violado.
\end{abstract}

Percebe-se que, enquanto Raskin atribui a construção do humor à passagem de um script a outro, do modo confiável ao não-confiável através de um gatilho linguístico, Veatch corrobora com essa visão agregando a possibilidade de um gatilho também não-verbal, pelo princípio de violação de um conhecimento, seja de base verbal ou não-verbal. Nestes termos, a teoria de Veatch, segundo ele intimamente atrelada à teoria de Raskin, contempla os aspectos extralinguísticos dos gêneros de humor e abre o leque da análise através de categorias mais abstratas, para além do verbal.

Veatch (1998, p. 195) retrata que:

\begin{abstract}
Raskin's theory is strictly limited to jokes, viewed as linguistic forms, or texts. Because of this restriction, it can't deal with differences that aren't in the text itself. It does not deal with humor that makes no use of linguistic means -- sight gags and slapstick, for example. It does not deal with differences in interpretation, such as jokes that fail in some situations but not others -- where, for example, a difference in perceived humor is related to differences in affective evaluations by different subjects, or to differences in the tension in a social situation, etc. Clearly humor is not restricted to jokes; the present theory relaxes this restriction. Since the present theory also generalizes over the classes of oppositeness-relationships that Raskin discusses, it may be seen in both respects as a generalization of Raskin's theory, to which it is otherwise closely related. ${ }^{7}$
\end{abstract}

\footnotetext{
${ }^{7}$ A teoria de Raskin é estritamente limitada a piadas, vistas como formas linguísticas, ou textos. Devido a esta restrição, não pode lidar com as diferenças que não estão no texto em si. Ele não lida com humor que não faz uso de meios linguísticos - gags visuais e pastelão, por exemplo. Ele não lida com as diferenças de interpretação, tais como piadas que falham em algumas situações, mas não em outras - onde, por exemplo, a diferença no humor percebido está relacionada com diferenças na avaliação afetiva por assuntos diferentes, ou a diferença na tensão 
É perceptível a ampliação de eixos temáticos e funções do humor. Mesmo assim, em ambas as teorias, a quebra da expectativa corresponde a um fator primordial à construção do humor, muito embora essa ocorra através de diversos fenômenos construtores da significação, como ambiguidade, vagueza, intertextualidade. Enfim, cabe ao leitor estabelecer as relações necessárias à compreensão dos scripts no texto e perceber, por meio de inferências, o que desencadeia o gatilho ou violação, gerando o humor.

Cabe ao leitor estabelecer as relações necessárias à compreensão do texto, ciente de que as informações não se apresentam de forma linear, explícitas, mas que, na sua grande maioria, precisam ser inferidas, seja no nível semântico ou pragmático, no contexto linguístico ou extralinguístico, verbal ou não verbal.

É com base nessa proposição que buscaremos visualizar como as inferências são importantes para a compreensão dos textos, aqui demonstrados através do gênero tirinha humorística, percebendo a riqueza presente no humor para o desenvolvimento da leitura na escola.

\section{Inferindo para Construir Sentidos}

É necessário clarificar que, embora não seja possível ensinar habilidades cognitivas de leitura (KLEIMAN, 1998), é fundamental estabelecer condições favoráveis a esse fim, oportunizá-las, colocando à disposição do leitor gêneros que forneçam aspectos textuais, condições estimuladoras que desafiem a capacidade de ir além da decodificação e, através da mobilização de fenômenos responsáveis pela significação ${ }^{8}$, constituir estratégias. Essa

uma situação social, humor, etc. Claramente não é restrita às piadas, a teoria atual relaxa nesta restrição. Uma vez que a presente teoria também generaliza sobre as classes de relações de oposições que Raskin discute, e desta forma, pode ser observada em ambos os aspectos, como uma generalização da teoria de Raskin, a qual é intimamente relacionada. (VEATCH, 1998, p. 195) (Tradução nossa)

${ }^{8}$ Consideramos neste estudo os conceitos de sentido e significado apresentados em Moura (2006), pois, para o autor, “... o sentido de uma sentença pode ser descrito, tecnicamente, como uma função de situações e significados. Em outros termos, calculamos o significado de uma sentença a partir do sentido dessa sentença e da situação em que ela é produzida" (MOURA, 2006, p. 63). Nesta visão, a referência, ou seja, aquilo de que se fala, segundo Moura (2006), não é constituída apenas com base no sentido, considerado elemento fixo da sentença, mas por intermédio do significado, que, por sua vez, é calculado com base na situação de enunciação, correspondendo ao elemento variável. 
compreensão direciona o leitor, despertando habilidades de leitura que se estendem a quaisquer gêneros, nas mais diversas situações comunicativas, direcionando-o à capacidade leitora.

Os gêneros de humor possuem essa característica desafiadora, visto que requerem que o leitor acione fatores linguísticos e contextuais para a apreensão do efeito de humor, pois, “... se tal efeito não se produz, não é 'sacado', pode-se ter razoável certeza de que o texto não foi interpretado segundo ele mesmo o demanda" (POSSENTI, 1998, p. 52).

Assim, Possenti (1998) expressa a consciência de que existem textos abertos a diversas interpretações, não sendo o caso dos gêneros de humor, que limitam as interpretações possíveis. Nessa construção, interagem significações no nível do explícito e do implícito, construídas na relação entre linguagem verbal e não verbal, fator que atraiu esta pesquisa para o desenvolvimento das habilidades de leitura em tirinhas de humor, por possibilitar o contato do leitor com a percepção dos sentidos, pela interrelação dos contextos semântico e pragmático no texto.

Trata-se, pois, como visto em Bergson (2001), do desenvolvimento da capacidade lógica de estabelecer relações entre os aspectos marcados no texto e os extratextuais, necessários à compreensão; de inferir, de ir além do nível do explícito e mergulhar no implícito, no subentendido.

Colocamo-nos, assim, diante de textos de humor que “...podem até permitir mais de uma leitura, mas frequentemente impõem só uma e geralmente impedem uma leitura qualquer" (POSSENTI, 1988, p. 78). Ao mesmo tempo, admitimos que são gêneros que “... do leitor exige-se a leitura do que não está dito, que se decodifiquem os subtendidos, o que não implica simples tentativas de apreender o que o locutor diz, mas o que ele pretende dizer o que diz" (FERRAZ, 2012, p. 114).

Visando atingir os objetivos propostos pela pesquisa, buscaremos apresentar uma base teórica para a compreensão das inferências nos textos de humor. O direcionamento adotado decorre da compreensão de que a capacidade de inferir consiste em um processo fundamental à formação de leitores proficientes e críticos, e essa capacidade pode ser desenvolvida por meio da contribuição dos textos de humor, dada a riqueza de fenômenos linguísticos mobilizados em sua produção.

Refletindo sobre os processos inferenciais, Cavalcante (2012, p. 31) explica que: 
conhecimentos entram em ação no momento em que articulamos as informações que se encontram na superfície textual (o cotexto) com outras que se acham armazenadas em nossa memória, acumuladas ao longo de nossas diversas experiências. É a partir dessas deduções que preenchemos várias lacunas deixadas pelo cotexto e fazemos antecipações, levantamos hipóteses sobre os sentidos do texto.

Compreendemos a inferência como processo previsível, ratificando a visão de que um texto não disponibiliza ao leitor a possibilidade de compreensão ilimitada, ou seja, nem todas as interpretações são possíveis, visto que embora interajam os diversos níveis de conhecimento, corroborando para a construção de verdades, essas são direcionadas pelo conteúdo linguístico do texto, através do qual estão presentes as intenções comunicativas do texto lido.

Para Koch (2012, p. 28), por meio do desenvolvimento das inferências, o leitor será capaz de estabelecer a ponte entre o dado, o material linguístico presente na superfície do texto, e os demais conhecimentos necessários para a significação, ou seja, os conhecimentos prévios e/ou compartilhados: “...é, em grande parte através das inferências que se pode (re)construir os sentidos que o texto implicita".

É necessário levar em consideração que a leitura é um processo no qual interagem autor e o leitor, por meio do texto. Dessa relação, defendemos que estão marcados, no texto, os caminhos possíveis à leitura, embora contribuam, nesse processo, os conhecimentos de mundo trazidos pelo leitor, os aspectos intertextuais, cabendo ao mesmo compreender os caminhos da construção da significação.

Reconhecemos que, na escola, e delimitamos aqui o grupo de alunos pertencentes ao Ensino Médio, essa realidade ainda se encontra distante, pois "Uma das características que empobrecem o ensino médio da língua materna é a pouca atenção reservada ao estudo da significação" (ILARI, 2012, p. 11), fato que promove um ensino e a formação de leitores caracterizados pela grande incapacidade de abstração e de desenvolver relações inferenciais, tornando-se leitores ingênuos e com sérias dificuldades de aprendizagem.

Ciente dessa necessidade, Travaglia (2004, p. 210) reafirma a necessidade de atividades de compreensão de textos que levem o aluno a reconhecer os recursos linguísticos que atuam na produção de efeitos de sentidos como estratégia para o desenvolvimento da capacidade leitora.

Reconhecemos nas tirinhas e no humor, do qual elas são constituídas, importantes ferramentas para propiciar esse contato e o desenvolvimento da capacidade leitora. As tiras 
disponibilizam, em um mesmo gênero, aspectos explícitos e implícitos, o que possibilita ao aluno desenvolver a capacidade de inferir os diferentes níveis de conhecimento.

Identificar as informações postas na superfície do texto, para o Ensino Médio, não condiz com uma tarefa difícil, uma vez que nessa fase os alunos já dispõem de certo amadurecimento linguístico. Todavia, é no nível do implícito que o problema torna-se mais grave, considerando que grande parte das informações de um texto encontra-se nesse nível.

É com base nessa percepção que verificamos, em Marcuschi (2008, p. 237-238), duas visões acerca das teorias de compreensão: de um lado, aquela que se baseia na hipótese de compreensão enquanto decodificação, tomando a noção de língua como código; e, do outro, a de compreensão enquanto inferência, baseando-se na visão de língua enquanto interação, processo comunicativo.

Buscando estabelecer um paradigma para o que chama de "paradigma inferencial", Marcuschi (2008, p. 239) pontua:

1 Ler e compreender são equivalentes.

A compreensão de texto é um processo cognitivo.

No processo de compreensão, desenvolvemos atividades inferenciais.

3 Os conhecimentos prévios exercem uma influência muito grande ao compreendermos um texto, dos quais fazem parte: os conhecimentos linguísticos, os factuais ou enciclopédicos, os pessoais, os de base institucional, cultural, histórico e social e os lógicos.

4 Compreender um texto não equivale a decodificar mensagens.

Compartilhando das afirmações apresentadas, faz-se necessário perceber que a leitura só se efetiva a partir da compreensão e essa, só por meio de atividades inferenciais, configurando-se enquanto processo cognitivo. Inferir, nesse contexto, diz respeito à capacidade de mobilizar os conhecimentos necessários à compreensão, ou seja, “... as estratégias cognitivas consistem em estratégias de uso do conhecimento" (KOCH, 2012, p. 35).

É, pois, através das inferências que o leitor é capaz de perceber não somente a construção dos sentidos, mas, sobretudo, os processos que foram mobilizados para fazê-lo, desde as escolhas lexicais, deslocamentos sintáticos, intertextualidade, referenciação, duplicidade de sentidos, enfim, o uso de elementos responsáveis pela construção da coerência textual e da efetivação do propósito comunicativo.

Segundo Rickheit, Schnotz \& Strohner (1985 apud Marcurchi, 2008, p. 240), as inferências são estratégias que consistem em gerar uma informação semântica nova com base em uma informação semântica já existente em um determinado contexto. 
A constituição dos esquemas inferenciais depende do reconhecimento de que o texto traz marcas linguísticas que determinam sentidos possíveis a serem construídos e que esses são delineados, guiados pela relação autor-texto-leitor e pelas marcas textuais que delimitam e direcionam os conhecimentos prévios a serem integralizados ao processo inferencial, de modo a gerar sentidos possíveis, com valor de verdade.

Coscarelli (2002) chama a atenção para o fato de que as inferências, independentemente da vertente classificatória utilizada, derivam do nível de complexidade do fenômeno mobilizado na construção do sentido, pois, enquanto estratégia, vislumbram os sentidos implícitos, ou seja, os pressupostos, acarretamentos e implicaturas, as múltiplas interpretações, os processos de indeterminação de sentidos, enfim, os diversos fenômenos da significação, assim como os diferentes níveis de conhecimento mobilizados na sua construção.

Por meio do reconhecimento e compreensão dos aspectos citados é que se ratifica a visão de que a leitura não é linear, que não há apenas uma compreensão. Segundo destaca Marcuschi (2011, p. 91), apoiando-se em Possenti (1990; 1991), "Não podemos dizer quantas são as compreensões possíveis de um determinado texto, mas podemos dizer que algumas delas não são possíveis. Portanto, pode haver leituras erradas, incorretas, impossíveis e não autorizadas pelo texto".

A esse respeito, Ferreira e Dias (2004, p. 440) afirmam:

\begin{abstract}
O leitor tem liberdade para construir sentidos, mas ele também é limitado pelos significados trazidos pelo texto e pelas suas condições de uso. $\mathrm{O}$ texto é gerado a partir dos significados atribuídos pelo autor quando em interação com seu mundo de significação, e é recontextualizado pelo leitor, que busca atribuir-lhe significado a partir da relação que mantém com o seu próprio mundo e com o autor, o qual delimita (sem oprimir) as possibilidades de construção de novos significados.
\end{abstract}

Ratificamos a pertinência das tiras humorísticas como gêneros de grande riqueza significativa para o desenvolvimento de inferências, cuja constituição oferece ao aluno a possibilidade de desenvolver a capacidade de realizá-las e reconhecê-las enquanto estratégias fundamentais à compreensão dos mais diversos textos.

Para Koch (1996, p. 161), "a intelecção de um texto consiste na apreensão de suas significações possíveis, as quais se representam nele, em grande parte, por meio de marcas linguísticas". Por essa razão, faz-se necessário preparar o aluno para ser capaz de reconhecer essas marcas e estabelecer as conexões necessárias e pertinentes à construção dos sentidos possíveis a cada contexto, como é o propósito deste estudo. 
É, pois, papel da escola transcender um estudo metalinguístico através do qual os alunos “decoram” conceitos gramaticais e, logo em seguida, esquecem-nos, visto que, o que não é vivenciado é facilmente descartado. É necessário levar o aluno a vivenciar as manifestações da linguagem em textos diversos, sendo os de humor de grande relevância, por, naturalmente, promover a vivência do leitor com situações linguísticas diversas, além de desafiá-lo à percepção destes mecanismos lógicos.

\section{Considerações Finais}

Decorrente de um recorte teórico, imerso em uma pesquisa ampla, este artigo traz presente reflexões teóricas necessárias à compreensão das relações possíveis entre os fenômenos constitutivos do humor e como eles sãos capazes de desencadear ações lógicoreflexivas, a exemplo das inferências, de modo a desenvolver habilidades cognitivas de leitura.

Levar estas reflexões aos diversos profissionais das áreas do ensino e dos estudos da linguagem é fazer suscitar novos caminhos em busca de uma aprendizagem mais efetiva, ou seja, de um fazer-se leitor autônomo e reflexivo.

\section{Referências}

ALBERTI, Verena. O riso e o risível na história do pensamento. Rio de Janeiro, Zahar: FGV, 1999.

BERGSON, Henri. O riso: ensaio sobre a significação da comicidade. Tradução de: Ivone Castilho Benedetti. São Paulo: Martins Fontes, 2001.

CAVAlCANTE, Mônica Magalhães. Os sentidos do texto. São Paulo: Contexto, 2012.

CORACINI, M. J. R .F. Leitura: decodificação, processo discursivo? In: CORACINI, M.J. R. $\mathrm{F}$ (Org.). O jogo discursivo na aula de leitura: língua materna e língua estrangeira. Campinas: Pontes, 2002a.

FERRAZ, Mônica Mano Trindade. Ensinando com textos de humor: sugestões de leitura do gênero charge. IN: PEREIRA, Regina Celi Mendes. (Org.) A didatização de gêneros no contexto de formação continuada em EAD. João Pessoa: Editora Universitária / UFPB, 2012. p. $95-124$. 
FIORIN, José Luiz; SAVIOLI, Francisco Platão. Para entender o texto: leitura e redação. São Paulo: Ática, 1990.

FREUD, Sigmund. 1959. Obras Completas de Sigmund Freud. Trad. C. Magalhães de Freitas e Isaac Izecksohn. Rio de Janeiro: DELTA, 10v. Parte 1: O Chiste e Sua Relação com o Inconsciente: 3-242.

ILARI, Rodolfo. Introdução à semântica - brincando com a gramática. 8.ed. São Paulo: Contexto, 2012.

Contexto, 2011.

Introdução ao estudo do léxico - brincando com as palavras. 5.ed. São Paulo:

Semântica e Pragmática: duas formas de descrever e explicar os fenômenos da significação. Revista de Estudos Linguísticos. Belo Horizonte, v.9, n.1, p. 109-162. Jan/Jun, 2000 .

KLEIMAN, Ângela. Oficina de leitura: teoria e prática. 6. ed. Campinas-SP: Pontes, 1998.

KOCH, Ingedore Villaça; ELIAS, Vanda Maria. Ler e compreender: os sentidos do texto. 5. ed. São Paulo: Contexto, 2011.

MAGALHÃES, Helena Maria Gramiscelli. Aprendendo com humor. Campinas-SP: Mercado de Letras, 2010. (Coleção Ideias sobre Linguagem)

MARCUSCHI, Luiz Antônio. Compreensão textual como trabalho criativo. Acervo digital UNESP, 2011. Disponível em: http://acervodigital.unesp.br /handle/123456789/40358. Acesso em: março de 2013.

Editorial, 2008.

Produção textual, análise de textos e compreensão. São Paulo: Parábola

POSSENTI, Sírio. Humor, língua e discurso. São Paulo: Contexto, 2010.

Os humores da língua: análises linguísticas de piadas. Campinas:

Mercado de Letras, 1998.

RASKIN, Victor. Semantic mechanisms of humour. Dordrecht: D. Reidel, 1985.

ROSAS, Marta. Por uma teoria da tradução do humor (The case for a theory of the translation of humor) [on line]. 2003. Disponível em <http://www.erudit.org/revue/meta/1989/v34/n1>, ISSN: 0026-0452.

SOLÉ, Isabel. Estratégias de leitura. 6.ed. Porto Alegre: ArtMed, 1998.

TRAVAGLIA, Luiz Carlos. Recursos linguísticos e discursivos do humor: humor e classe social na televisão brasileira. In: XXXVI Seminário do Grupo de Estudos Linguísticos do Estado de São Paulo, 1989, São Paulo. Estudos Linguísticos - XVIII anais de seminários do 
Grupo de Estudos Lingüísticos do Estado de São Paulo. Lorena: Prefeitura Municipal de Lorena / GEL-SP, 1989. v. XVIII. p. 670-677.

VEATCH, Thomas C. (1998). A Theory of Humor. Humor: International Journal of Humor Research, Berlin: Mouton DeGruyter, vol. 11. n.2. pp. 161-216. Disponível em: http://www.tomveatch.com/else/humor/paper/. Acesso em: dezembro de 2012.

\section{Como citar este artigo (Formato ABNT):}

UCHÔA, Sayonara Abrantes de Oliveira; OLIVEIRA, Symara Abrantes Albuquerque de; SILVA, Henrique Miguel de Lima Silva; OLIVEIRA, Gislene Farias de. Humor e Significação: revisitando bases teóricas. Id on Line Rev.Mult. Psic., 2018, vol.12, n.42, p.22-37. ISSN: 1981-1179.

Recebido: 03/07/2018.

Aceito: 03/08/2018 